\title{
VI.
}

\section{Ein Fall von septischer Pnenmonie beim Neugebornen, verursacht durch den Bacillus enteritidis (Gaertner).}

\author{
Von Dr. O. Lubarsch, \\ Privatdacenten and Assistenten an Pathologiscben Institur in Zirich \\ unter theilweiser Mitarbeiterschaft von \\ Dr. H. Tsutsui aus Tokio ${ }^{3}$ ).
}

(Hierzu Taf. I.)

Am 7. Närz d. J. wurde im hiesigen pathologischen Institut die Leiche eines 2 tägigen Kindes von mir secirt, bei der die klinische Diagnose auf Winkel'sche Krankheit oder Sepsis lautete. Das Kind war am 4. Mär Abends $10 \mathrm{Uhr} 30 \mathrm{Min}$. in der hiesigen Frauenklinik in der 2. Schädellage geboren worden. Der Krankengeschichte, welche ich der Güte des Directors der Klinik, Herm Prof. Dr. Wyder, verdanke, entnehme ich Folgendes.

Kind Giessling hat 5. März den Tag über gut geschlafen; Abends fiel es der Wärterin auf, dass der Stubl merkwürdig übel roch und grüngelb aussah. Bis gegen Mitternacht blieb das Kind ruhig, fing dann aber an beständig zu wimmern. Am 6 . wieder die äbelriechenden Stühle und eigenthümlicher, die Windeln brannröthlich färbender Harn. Das Kind im Gesicht dentlich cyanotisch, respirirt beschleunigt (60 Athernzüge in der Minute). An den Lungen lässt sich weder percutorisch, noch auscultatorisch etwas nachweisen. Athmung fast ausschliesslich costal, das Abdowen etwas aufgetrieben, aber nirgends sichtbar druckempfindlich. Am $\mathrm{N}$ abel gar nichts Auffälliges, am Rücken blänliche Flecken, ebenso an den unteren Extremi-. täten. Der aufgefangene Harn enthält kein Eiweiss. Hämoglobinprobe mit Kalilauge fallt negativ aus. Der Barn setzt sebr rasch starkes Sedimentum lateritium ab. Gegen Abend Zunahme der Oyanose und Athemoth. Temperatur im Rectum 36,50. Abends 8 Uhr constatirte die Wärterin den Tod.

Klinische Diagnose wegen des negativen Befundes am Nabel, Winkel'sche Krankbeit? oder Sepsis?

Die ron mir 13 Stunden p. m. ausgeführte Section hatte folgendes Ergebniss:

1) Herr Dr. Tsutsui, der wesentlich an dem bakteriologischen Theil dieser Arbeit betheiligt ist, wurde durch seine plötzliche Abreise nach Japan von der weiteren Betbeiligung abgehalten. 
- ar.

8 0 ,

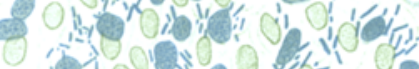

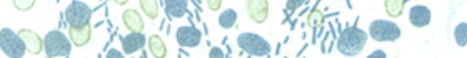

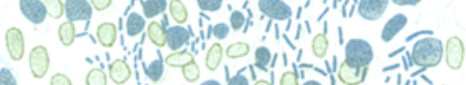

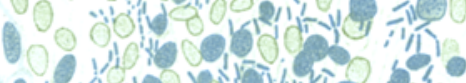
1

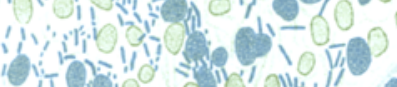
- iT io sin mini 0 .11 0 N $\left.4 y^{1}\right)^{2}$
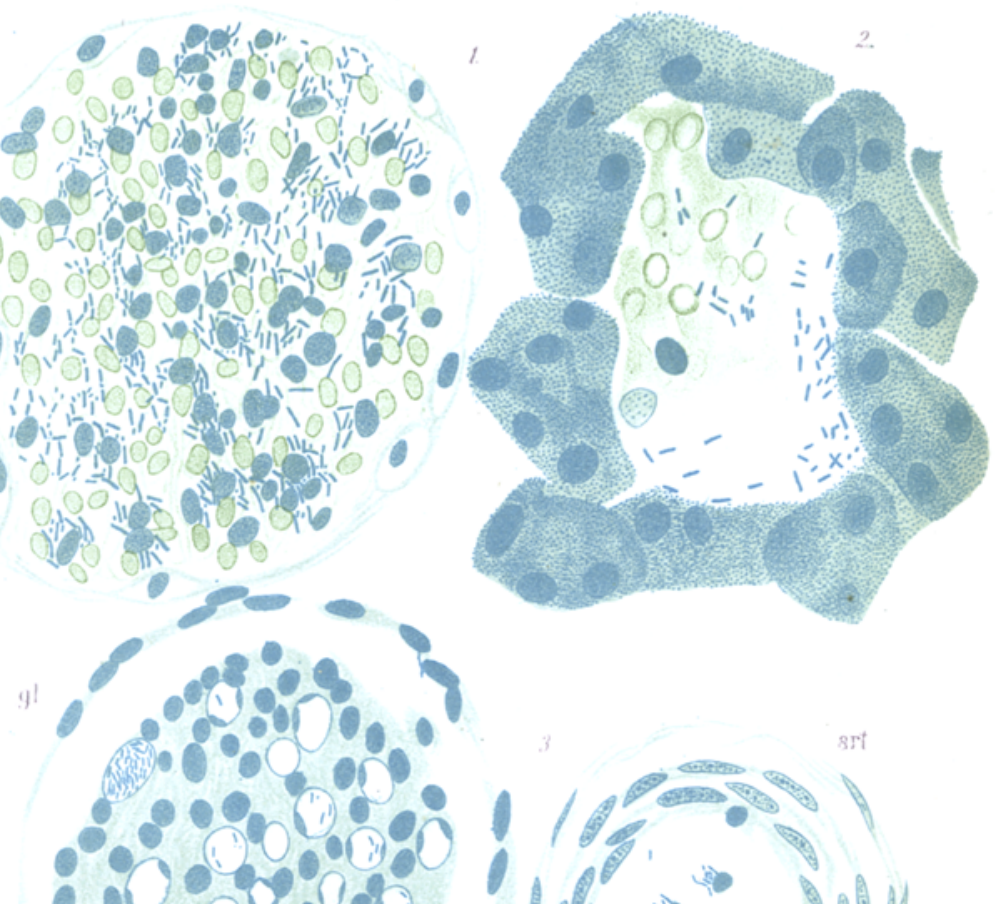

100000 . 10 . of

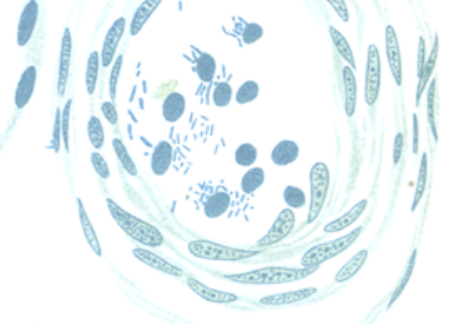

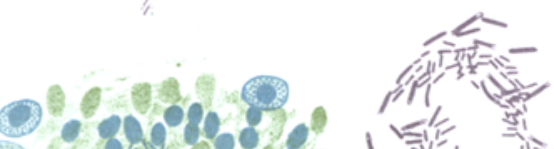

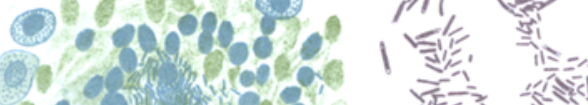

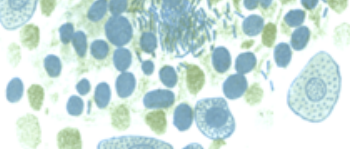

다요

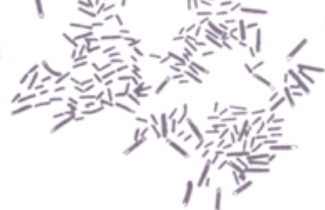

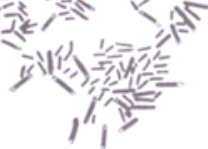

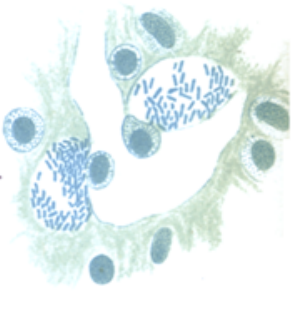


Kindliche Leiche männlichen Geschlechts, wit leichter icterischer Verfärbung der Haut und Conjunctiva, sowie ausgedehnter Lanugobehaarung. Ernährungszustand durchaus normal. Nabelvenen und Arterien werden nach Eröffnung der Bauchböble weit verfolgt und genau untersucht. Die Vene enthălt dunkle Blutgerinnsel, Arterie fast vollständig leer. Weder die Intima noch die Adventitia lassen Veränderungen erkonnen, auch auf dem Querschnitt erscheinen die Gefässe intact. Ebenso aussen und innen am Nabel nichts Abnormes wabrnebmbar. Zwerchfellstạnd links am unteren Rand der 6., rechts am oberen der 5. Rippe. Gleich nach Eröfinung der Brusthöhle bemerkt man im linken Pleuraraum etwas trübe und schlecht riechende Flüssigkeit, die mit grünlich-gelblichen Flecken untermischt ist. Von aussen betrachtet erscheint die linke Lunge im Oberlappen gut lufthaltig, im Unterlappen sehwer und resistent. Im Herzbeutel wenige Tropfen Flüssigkeit. Epicard enthält wenig Fett. Herz normal gross; Klappen zart, Ventrikel und Vorböfe von normaler Weite; im rechten Herzen dunkle Blutgerinnsel. Ductus Botalli durchgängig. Die linke Lunge zeigt die Pleura im Unterlappen in ganzer A usdehnung getrübt und mit grün-gelblichen, grösstentheils leicht abziehbaren Fetzen bedeckt. Auf der Schnittfläche ist der untere Lappen dunkelblauroth, vollkommen luftleer, nicht eigentlich körnig; es sind keine einzelnen Heerde vorhanden, sondern das ganze Gewebe ist, ohne dass eine deutliche Abgrenzung irgendwo sichtbar ist, gleichmässig hepatisirt. Mit dem Messer lässt sich träbes, bräunliches Exsudat abstreifen; auch dieses riecht übel. Die ganze Substanz brüchig. In den Bronchien beider Lappen befindet sich eitriger Schleim; die Schleimhaut stark geröthet. Rechte Lunge im Ganzen völlig lufthaltig, zeigt nur im Unterlappen einige bläuliche Flecke an der Pleura, denen im Lungengewebe gleichartig gefärbte Juftleere Stellen von fast keilförmiger Gestalt und etwas eingesunkener Oberfäche entsprechen, sonst die rechte Lunge völlig lufthaltig und blutreich. Bronchien wie links. Der unterste Theil der Trachealschleimbaut stark geröthet. Kehlkopfs- und Pharynxschleimhant blauroth, sonst hier Alles normal. Milz etwas vergrössert, auf dem Durchschnitt ziemlich fest, dunkelroth. Nebennieren gross, ohne Veränderungen. Nieren mit leicht abziehbarer Kapsel, zeigen leichte Trübung der Rinde und besonders rechts reicblich Harnsäureinfarcte der Pyramiden. Leber ebenfalls vergrössert, Schnittfläche sehr blutreich, etwas getrübt, auffallend brann. Magen und Duodenum völlig ñormal. Der gesammte Darm von oben bis unten genau untersucht, zeigt ausser stellenweise stärkerer lnjection der Schleimhaut keine Besonderheiten; der Inbalt ist im Ganzen dünnflüssig, gelblich. Harnblase enthält nur einige Tropfen gelb-braunen Urins.

Anatomische Diagnose: Pleuritis und Pneumonie des linken Unterlappens. Beiderseitig eitrige Bronchitis. Atelectasen der rechten Lunge. Parenchymatöse Trübung der Nieren, Fettinfiltration und Stauung der Leber. Leichter Milztumor. Barnsäureinfaret der Nieren. Icterus neonatorum.

Die frische Untersuchung der Organe in Schnitt - und Zupfpräparaten ergab am Berzen völlig normalen Befund, in den Nieren parenchymatöse Trübung und stellenweise Fettmetamorphose der Epithelien der gewundenen 


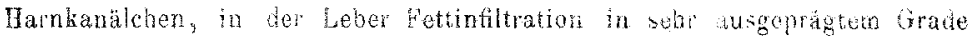
und Stanung.

Die mikroskopische Untersuchung der meistentheils in Siblimat gebärteten und in Paraffin eiugebetteten Organe ergab nun folgende Verhälnisse (Farbung theilsmit Hämatoxylin-Eosin, theils mit Sahli's Borax-Blethylerblau).

Linke It unge zeiogt die Veränderungen einer katarhaliseh-hämorhagisehen Preuponie. Die Alveolen sind ausgefillt mit einem lixsudat, das grösstentheils aus weisson wnd rothen Blutkörperchen bestebt, dem hio und da auch geguellene und desquamirte Alvolarepithelien beigemischt sind; meistentbeils sind rothe una weisse Blutköper in ziemlich gleicher. Zahl vorhanden, an einzelnen Stellen bestebt das Rxsudat jedoch fast ausschliesslich aus rothen Blutkörpern. Fibrin ist in Ganzen nur spärlich beigemischt. Dicht unter der Pleura liegen mehrfach recht grosse Hämorbagien. Witten zwischen den Zellen oder den Fibrinmassen des Exsudates finden sich nun die Bacillen in sehr grosser Anzahl, hie und da zerbröckelt, nicht selten auch jm Innern pon weissen Blutkörperchen (Fig. 1). A $\mathrm{m}$ reichlichsten sind sie in den subpleuralen Hämorrbagien und den fibinốsen Auflagerungen der Pleura. In den Bronction findet sich ebenfalls ein Bxsudat, das fast ausschliesslich aus Leukocyten und wenig rothen Blutzörpero bestebt; Bacillen sind hier meistens nur spärlich, an enigen Stellen aber geradexu massenhaft zu finder. Dio Capillaren der Lunge sind grösstentheils erweitert und mit rothen Blutkörperchen stark gefüllt; doch zeigen auch manche, ebenso wie kleinere Venen und Arterien, eine ausgeprägte Lenkocytose; sie alle enthalten die Bacillen in wechselnder aber stets reichlicher Menge.

Rechte Lunge zeigt grösstentheils völlig freie und normale Alveolen, ebenso die grösseren Bronchien frei; nur in einigen Bionchiolis liegt zelliges Exsudat, die dazu gehörigen Alveolen sind mit desquamirten Alveolarepithelien und wenigen rotben Blutbörpercben gefillt; in einer Alveole, die reichlicher rotbe Blntbörper enthält, finden sich einige Bacillenhaufen. Sowohl die Capillaren, wio anch grössere Arterien und Venen sind mit rothen Blutkörperchen förmlich vollgepfropt; einige Capillaren zeigen deutliche I reukocytose. In allen Blutgefässen liegen die Bacillen, bald meir, bald weniger reichlich meistentheils dicht cer Intima an, in grösseren Gefässen auch frei in Lumen.

Milz zeigt wesentlich eine Anbäufung von rothen Blutröpen in den Gefässen, sowie in den Pulpasträngen. Die Follikel erscheinen sehr zellreich, häufig sieht man in der Pulpa neben Leukoçten mit. einem und mehreren Kernen grössere Zellen nit zum Theil körnigen Protoplasma und grossen Kernen. Hier liegen dann die Bacillen moistentheils in Flaten ganz wie die Typhusbacillen (Fig. 4). Femer sieht man die Bacillen oft in reichlichen Mengen die Capillaren ausfülen, ja dann und wann förmlich verstopfen.

Die Nieren zeigen an einzelnen Stellen körnige Massea in dem Kapselraum der Glomeruli; in den Sammelröbren liegen ofter börnige, sehr selten hyaline Cylinder und noch spärlicher rothe Blutkörperchen. In einem Präparat wurden spärliche Bacillen im Kapselraum und einem Harnkanälchen gefundeu. Die Bacillen lagen sonst zu Haufen in den Glomerulus- und inter- 
tubulären Capillaren; in der ganzen Niere enthalten die Gefässe äberwiegend weisse Blutzörperchen; die Füllung mit rothen tritt entschieden zurück.

Die Leber zeigt starke körnige Trübung der Leberzellen und Fettinfiltration: ausserdem hochgradige Staung; die Capilaren enthalten sowohl massenhaft rothe Blutkörper, wie reichlichst Leukocyten mit vielfach zerfallenden Kernen. Die Bacillen liegen in grosser Anzahl überall in den Gefässen, meistentbeils dicht der Capillarwand an, mitunter auch in Endothelzellen.

Vom Darm wurden nur solche Stellen untersucht, die auch makroskopisch verändert erschienen. Es zeigten sich Schwellung der Follikel und Peyer'schen Haufen, sehr starke Injection aller Gefässe wit weniger auffälliger Leukocytose; hie und da bleine Hämorrhagien in der Submucosa. An der Schleimhautoberfläche sind sowohl mit der Sahli'schen, wie Löffler'schen Färbung und der Weigert'schen Methode Bakterien nur in äusserst geringer Zahl nachweisbar; Gärtner'sche Bacillen überhatpt nicht, sondern nur Kokken und dicke, längere Stäbchen. In der Submucosa und Huscularis finden sich dagegen die Gärtner'schen Bacillen sehr reichlich in kleineren und grösseren Gefässen.

Die Nabelvene zeigt völlig normale Structuren; an der Intima liegen spärlich die Bacillen, reichlicher dagegen in den Gefässen der Adventitia.

Zur bakteriologischen Untersuchung wurden unter den allgemein bekannten und geübten Cautelen, bevor die betreffenden Organe aufgeschnitten wurden, Stücke von dem Unterlappen der linken Lunge und der Milz benutzt. Von jedem Stück wurden 4 Platten auf $1 \frac{1}{2}$ procentigem Agar-Agar angelegt und diese der Temperatur des Koch'schen Brütschrankes ( $37^{\circ} \mathrm{C}$.) ausgesetzt. Bereits nach 24 Stunden fanden sich sïmmtliche Platten mit Heerden bedeckt, die alle das gleiche Aussehen darboten. Die oberflächlichen Colonien waren etwas über stecknadelkopfoross, grauweiss, leicht schleimig, die tief gelegenen ebenfalls weisslich, etwa halb so gross, wie die oberflächlichen Heerde. Die letzteren erscheinen bei schwacher Vergrösserung rundlich, mitunter citronenscheibenförmig, 'grob gekörnt, mit unregelmässigen, aber scharfen Rändern; die oberflächlichen Heerde waren etwas feiner gekörnt. Diese Heerde bestanden nun, wie das Mikroskop zeigte, ausuahmslos aus Bacillen, welche meist von kurz-ovaler Form waren, aber auch längere Individuen zeigten; sie besassen, im hängenden Tropfen untersucht, deutliche, wenn auch nicht sehr lebhafte Eigenbewegung; häufig lagen sie zu zweien an einander gereiht. Färbung mit 1 procentiger wässeriger Gentianviolettoder 2 procentiger Methylenblaulösung war nicht sebr intensiv, 
dagegen gelang die Eärbung mit Löffler"schem Kali- oder Sahli"schem Boraxmethylenblau vorzïglich. Bei Anwendung des Gram'schen oder Weigert'schen Verfahrens trat völlige Entfärbung ein. Nach Feststellung dieses Verhaltens wurde ich von Herm Dr. Tsutsui, der früher unter Leitung von Herrn Prof. Gaertner mit dem Bacillus entcritidis gearbeitet hatte, darauf aufmerksam gemacht, dass, eine grosse Achnlichkeit zwischen den von mir gezüchteten Bacillen and jenen bestände. Unsere gemeinschaftliche weitere Untersuchung richtete sich daher zunächst darauf, die Identität mit dem Bacillus enteritidis festzustellen. Zn diesem Zwecke wurden vielfach veränderte Züch-

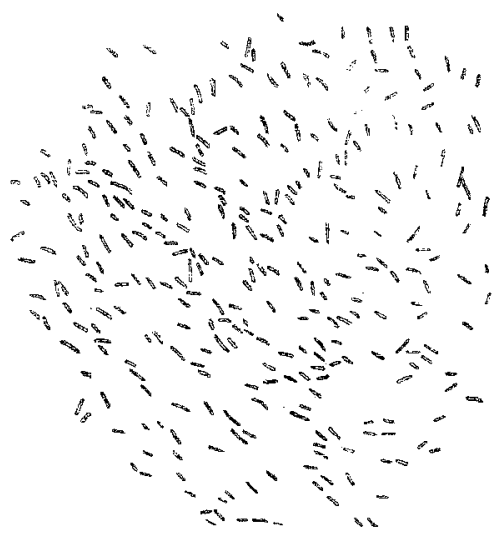

Aus einer Reincultur auf Agar tungen und Thierversuche angestellt. Auf Gelatineplatten zeigten unsere Colonien im Ganzen dasselbe Verhalten, wie auf den Agarplatten, die Colonien waren jedoch mehr weisslich und behielten diese Farbe länger bei, während die Heerde auf Agar-Agar schon nach einigen Tagen eine mehr graugelbliche Farbe annehmen; die einzelnen Bacillen erschienen etwas grösser, anch dicker $\begin{array}{ll}\text { (24 Stunden alt). Zeiss } \frac{1}{2}, \text { Oe. 2. } & \text { und zoigten hie und da eine } \\ \text { Ungefärbt. Präp. im bängenden Tropfen. } & \text { ungleichmässige Färbung der }\end{array}$ Art, dass die deutlich abgerundeten Enden ungefürbt blieben, während das Mittelstück deutlich gefärbt war (vgl. Fig. 6). Doch waren solche Formen weder sehr reichlich, noch sehr deutlich vertreten; sehr schön dagegen konnte dasselbe beobachtet werden auf 8 procentiger Gelatine, die $1-2$ pCt. Tranbenzucker enthielt. Im Impfstich auf Gelatine wächst der Bacillus nur dem Stich entlang ziemlich langsam, eine Verlïssigung tritt nicht ein, an der Oberfläche bildet sich ein grawweisser Bolag, der allmählich zu einer faltigen Haut wird und einsinkt. Auf schrägem Agar bildet sich ein grauweisser bis graugelblicher Belag, der an den Rändern etwas durchscheinend ist und leicht schleimig aussieht. Auf Bchring'schem schrigem Lakmusagar bringt 
der Bacillus bald eine deutliche Blaufärbung hervor, während er im Stich in Lakmusagar nur die Oberfläche bläut, die übrige Agarmasse aber vollständig entfärbt. In Bouillon wächst der Bacillus sehr rasch unter Trïbung der Flüssigkeit und bleibt schliesslich als gelblicher Bodensatz liegen; Milch bringt er bei Brütschranktemperatur in 24 Stunden zu flockiger Gerinnung. Auf der Kartoffeloberfäche bilden die Bakterien grauweisse bis graugelbe, feucht glänzende Beläge, die schon nach 24 Stunden (bei Brütschranktemperatur) deutlich sichtbar sind. Mitunter nahm diese Farbe bei längerem Stehen einen fleischfarbenen Ton an. $\mathrm{Zu}$ den Thierversuchen wurden Meerschweinchen, Kaninchen, weisse Mäuse, Tauben, weisse Ratten und Hühner benutzt. Die beiden letzteren Thierarten crwiesen sich bei jeder Art von Infection immun; sowohl subcutane, wie intraperitonäale Impfung versagten und auch rom Magen aus konnten Ratten nicht inficirt werden, obgleich sie mit grossen Massen von Organen solcher Neerschweinchen gefüttert wurden, die nach Impfung mit dem Bacillus gestorben waren. Am empfänglichsten erschienen Meerschweinchen und Kaninchen, an denen eine grössere Anzahl von Versuchen angestellt wurden. Dieselben erlagen bei intraperitonäaler Impfung mit einigen Cubikcentimetern Bouilloncultur in 16-24 Stunden, bei subcutaner Impfung mit einer Platinöhse Agarcultur nach 2-4 Tagen. Immer fand sich bei der Section starke Injection der Därme und Schwellung des Follikelapparats, einige Male auch kleine Blutungen in der Schleimhaut; serösfibrinöse oder hämorrhagische Peritonitis war bei intraperitonäaler Impfung stets vorhanden, bei subcutaner fand sich sowohl bei Kaninchen, wie bei Meerschweinchen einige Male serös-fibrinöse Pleuritis, mit Lungencompression, einmal mit einer circumscripten Pueumonie im Unterlappen; an der Impfstelle war bald fibrinöshämorrhagische Entzündung, bald starkes Oedem nachweisbar; die Milz war niemals bedeutend geschwollen. Die Bacillen waren durchschnittlich nicht sehr reichlich in den inneren Organen (Milz, Leber, Niere, Lunge und Herzblut) nachzuweisen, so dass sie in Ausstrichpräparaten hie und da vermisst wurden, in den entsprechenden Sohnittpräparaten jedoch stets auffindbar waren; sehr reichlich waren sie stets in den peritonitischen und pleuritischen bezw. subcutanen Exsudaten vorhanden, aus dem 
Darm wurden sie 2mal in Reincultur gezuchtet. Eine Intection vom Magen aus gelang weder bei Meersohweinchen noch bei Kaninchen. - Bej weissen Mäusen wurde - mit Ausnahme eines Falles, wo nur Eiterung an der Imptstelle auftrat - bei subcutaner Impfung der. Tod innerhalb 24-52 Stunden herbeigefüht; auch hier war Entzündung der serösen Hänte (bes. Pleura) vorhanden, in den inneren Organen waren dic Bacillen weit reichlicher vertreten, als bei Kaninchen und Meerschweinchen. Auch rom Magen aus konnten 2 Mäuse inficirt werden; 2 Thiere, denen Kartoffelculturen am 5. April zum Fressen gegeben wurden, starben am 7. April. Da ich gerade vereist war, konnte die Untersuchung erst am 8. vorgenommen werden, wo sine Maus bereits stark in Fänlniss übergegangen war; daher konnte hier kein sicheres bakteriologisches Resultat gewonnen werden: bei der anderen konnten jedoch noch durch die Cultur im Darm und Milz die eingeführten Bacillen nachgewiesen werden. - 2 Tauben blieben bei subcutaner Impfung gesund; bei intraperitonäaler starben sie jedoch nach etwa 18 Stunden. Sectionsbefund: fibrinöse Peritonitis, starke, zum Theil hämorrhagische Enteritis; im Herzblut, Leber und Milz ziemlich reichlich unsere Bacillen. - Um die toxische Wirkung des Bacillus zu prüfen, wurden an Meerschweinchen Versuche mit sterilisirten Bouillonculturen angestellt. Intraperitonäale Injection von $13 \mathrm{~cm}$ wurde noch vertragen, nach Einspritzung ron $26 \mathrm{ccm}$ jedoch starben die Thiere sehr rasch. Schon wenige Stunden nach der Einspritzung sassen die Thicre aneinander gekauert mit gesträubten Haaren da und begannen bald kläglich zu wimmern; sie machten deutlich den Eindruck, als ob sie frören. Bereits 14 Stunden nach der Implung wurden sie todt gefunden. Bei der Section fand sich fibrinös-hämorrhagische Peritonitis und Enteritis; zum Beweise, dass völlig sterile Bouillon eingespritzt war, wurden von dem peritonäalen Erguss und den inneren Organen reichlich Platten angelegt; dieselben blieben völlig steril ${ }^{\perp}$ ). War somit auch eine stark toxische Wirkung des Bacillus er-

Ausgenommen die Platten von dem peritonäalon Lirguss eines Ieerschweinchens, welches 2 weifellos etwas fruber gestorben war. Hier fanden sich auch mikroskopisch einige Darmbakterien, nirgents aber - auch in den Platten nicht - unser Bacillus. 
wiesen, und stimmte auch in den meisten anderen Punkten unser Bacillus mit dem Gärtner'schen überein, so hielt doch vor allem der Umstand, dass die Versuche, Meerschweinchen vom Magen aus zu inficiren, negativ ausgefallen waren, mich davon $a b$, ohne Weiteres die Identität unserer Bacillen mit deo Gärt ner'schen auszusprechen. Aus diesem Grunde schickte ich sowohl Culturen, wic Präparate vov den Organen des Neugebornen an Herrn Prof. Gärtner mit der Bitte, seine Ansicht über den Fall mir mitzutheilen. Herr Prof. Gärtner war so liebenswürdig, eine nähore Entersuchung vorzunehmen und theilte mir die Ergebnisse derselben in einem Briefe mit, den er mir zugleich zur Mitveröffentlichung überliess. Herr Prof. Gärtner schreibt: "Morphologisch kann ich zwischen Ihren Bacillen und den von mir in der Frankenhauser Fleischvergiftung geíundenen nur den einen Unterschied entdecken, dass Thre Mikroorganismen etwas grösser sind. Der Grössenunterschied ist indessen nicht so beträchtlich, dass ich eine andere Art von Bakterien annehmen möchte, höchstens eine andere Rasse ..... Die von mir gezüchteten Frankenhauser Bacillen besassen eine stark toxische Wirkung, welche auch durch Kochen nicht verschwand. Ich konnte Meerschweinchen innerhalb weniger Stunden bis zu $5 \mathrm{Ta}$ gen tödten, wenn ich sie mit einer Bouillon fütterte, welche dadurch erhalten war, dass ich keimfreies Fleisch mit den Bacillen in einer Fleischhackmaschine zerrieb, einige Tage stehen lioss und dann kochte. Mäuse, welche das ausgekochte Fleisch frassen, starben unter Vergiftungserscheinungen in wenigen Stunden .... Mit den von Ihnen gezüchteten Bakterien stellte ich einen ähnlichen Versuch an. Das geimpfte Fleisch roch nach 3 tägigem Stehen bei Zimmertemperatur und Itägigem Stehen bei Brüttemperatur säuerlich, aber es stank durchaus nicht. 4 Meerschweinchen, welche 24 Stunden gefastet hatten, erhielten mittelst Schlundsonde je $50 \mathrm{ccm}$ oben beschriebener Bonillon eingeflösst. Frkrankung trat nicht ein. 5 Häuse wurden mit dem geimpften und ausgekochten Fleisch gefüttert. 2 davon waren am nächsten Morgen, d. h. in etwa 20 Stunden, todt, eine am 2. Tage Morgens und die beiden übrigen am 4. Tage Morgens bezw. Mittags. Eine Todesursache konote pathologisch-anatomisch nicht gefunden werden. Nun sterben weisse Mäuse allerdings in 
cinigen Tagen, wenn man sie consequont mit gutem, gekochtem Fleisch füttert, aber die 3 ersten Thiere sind eutschieden an Vergiftung durch das inficirte und dann gekochte Fleisch gestorben, bei den 2 letzten kann man zweifelbaft sein, obgleich ich anch hier Giftwirkung annehmen möchte. - Der von Ihnen gefundene Oryanismus wirkt also toxisch, aber entschieden weniger, als der aus dem Frankenhauser Rind gezüchtete. Es ist das aber - meiner Ansicht nach - kein Grund eine Verschiedenheit beider Bacillen anzunehmen, denn die Giftigkeit ist entschiedea bedeutenden Schwankungen unterworfen."

Nach diesen Mittheilungen Prof. Gärtner's, der ja schliesslich der besto Kenner seines Bacillus ist, halte ich es auch nicht mohr für angebracht, an der Identität beider Bacillenarten zu zweifeln, um so mehr als ja die gefundenen Unterschiede überhaupt sehr geringfügig sind. Eine andere wichtige Frage, welche auch Herr Prof. Gärtnor in seinem Briefe nufwirf, ist nun aber die, ob unsere Bakterien wohl charakterisinte, specifische Krankheitserreger sind, die stets eine rasch tödtlich verlaufende Krankheit erzeugen, oder ob es Fäulnissorganismen sind, welche, für gewöhnnlich ganz oder fast ganz unschädlich, unter gewissen Bedingungen toxische Wirkungen entfalten lrönnen. Ss unterliegt ja keinem Zweifel, dass es eine Reihe von Bakterien giebt, die za den ron Hüppe als "Typhusgruppe" bezeichneten Organismen gehören und mit unseren Bacillen in vielen Punkten sehr uboreinstimmen. Die Abgrenzung derselben von gewöhnlichen Darmbakterien, bes. vom Bacterium coli commune (Escherich), ist durchaus nicht leicht, um so mehr, als auch diesem Organismus gewisse infectiöse Eigenschaften, wenn auch keine toxischen Wirkungen zukommen. Eine um so grössere Wahrscheinlichkeit würde $j a$ der Annahme von einer nur gelegentlichen Unwandlung in einen pathogenon Organismus verliehen werden, wenn man der Anschaung von $\mathrm{Tavel}{ }^{1}$ ) and $\mathrm{O}$. Wyss ${ }^{2}$ ) bejpflichtete, dass anch das Bacterium coli commune hie und da beim Menschen

1) Tayel, Das Bacterium coli commune ats pathogener Organisious und die Infection vom Darmkanal aus. Correspbl. f. schweizer Aerzte. 1889. No. 13.

;) Wyss, Ueber eine acute tödtiche Infectionskrankheit beim Säuging, bedingt dureb Bacterium coli commune. Tagbl. d. Versamml deutsch. Yaturf. u. Aerzte. Heidelberg 1889. 
infectiös wirken kann. Auch ich selbst habe einen Fall beobachtet, der den Gedanken an eine derartige infectiöse Wirkung des Bacterium coli commune aufkommen liess. Ein College erkrankte unter Erscheinungen, welche den Arzt zunächst zu der Diagnose Typhus abdominalis veranlassten. Die dem pathologischen Institut zur bakteriologischen Untersuchung übersandten, übrigens sehr übelriechenden Fäces enthielten nun aber, wie meine Untersuchung ergab, keine Typhusbacillen, sondern das Bacterium coli commune in Reincultur. Der weitere Verlauf der Krankheit war dann ein derartiger, dass die Aerzte an der Diagnose Typhus kaum noch festhielten und sich mehr der Auffassung zuwandten, dass es sich um ein einfaches, sog. gastrisches Fieber handle. Bei den von mir gezüchteten Bacillen fiel nun auch auf, dass ihre Beweglichkeit sehr deutlich war und eine Trübung der Gelatine nie eintrat. Angesichts dieser Thatsachen muss man die Frage aufwerfen, haben es Tavel und Wyss, habe ich es in dem letzten Fall wirklich mit Bacterium coli commune zu than gehabt oder handelte es sich auch hier um den Bacillus Gaertner. Die Uebereinstimmung in den Wirkungen ist in sämmtlichen Fällen keine geringe; immer zeigt der Bacillus Neigung zu hämorrhagischen Affectionen, auch bei Tavel, auch bei Gärtner; immer findet eine Wirkung auf den Darm statt, fast immer sind die Stühle übelriechend (Tavel und meine beiden Fälle). Die Abweichungen in dem morphologischen und culturellen Verhalten sind sowohl gegenüber dem Bacillus Gaertner, wie dem Bacterium coli commune geringe; die toxische Wirkung ist von Tavel und Wyss überhaupt nicht geprüft worden. Allerdings bestehen in der infectiösen Wirkung Unterschiede, dahin, dass die Bacillen yon Wyss und Tavel Neerschweinchen bei subcutaner Impfung nicht immer tödteten und bei Kaninchen noch weniger pathogen waren. Aber alles das liesse sich durch den Hinweis erklären, dass die infectiöse und toxische Wirkung bekanntermaassen Schwankungen ausgesetzt ist und dass die Bacillen von Tavel und Wyss abgeschwächte Species waren. Allein umgekehrt könnte man auch annehmen, dass Gärtner's und mein Bacillus, ursprünglich ebenfalls mit dem Bacterium coli commune identisch, ganz besonders starke infectiöse und toxische Eigenschaften erworben hatte, wäh- 
rend die l'avel'schen wa Wyss'schon Bacillen sich nooh in bescheidenen Grenzen hielten. Immerhin erscheint os mir doch noch nicht gerechtfertigt, so ohne Weiteres anzunehmen, dass oin sonst unschädlicher Darmbewohner unter Emständen so schwere toxische und infectiöse Eigenschaften entfalten könne; ich lann mich daber nicht Escherich ansohliessen, der in der Discussion uber den Fall von $O$. Wys meinte, die Möglichkeit des Vorkommens solcher Infectioneo wäre schon damit gegeben gewesen, dass den im normalen Milchkoth vorkommenden Bakterien pathogene Eigenschaften für Thiere zukämen. Vielmehr muss man es vorläufig doch noch für möglich haltẹn, dass es sich um allerdings sehr nahe verwandte Organismen handelt, von denen die einen normale Bewohner des Darmes durch Anpassung an ihren Wohnsitz toxische und patbogene. Eigenschaften völlig verloren haben, während andere, nur zufällig in den Thierkörper gelangende, diese Fähigkeit noch in stärkerem Maasse besitzen. Allerdings würde dagegen wieder die Angabe von Karlinski ${ }^{1}$ ) sprechen, dass er den Bacillus enteritidis zweimal im ganz normalen Kothe (eines Menschen und einer jungen, gesunden Ziege) faud. Aber da der Nachweis wohl nur durch die Cultur geführt wurde (nähere Angaben fehen), so ist es möglich, dass es sich um das Bacterium coll commune handelte. Jedenfalls lässt sich die Frage zur Zeit noch nicht entscheiden; eine Ansicht, die auch Herr Prof, Gärtner theilt. Denkbar ist es ja allerdings, dass, wie Prof. Gürtner, schreibt „unter gewissen Verhältnissen, z. B. unter anderen chemischen Bedingungen, ein Mikroorganismas einen Giftstofi bildet, den er für gewöhnlich nicht producirt. Der locale Reiz ermöglicht dann ein Durchtreten der. Mikroorganismen durch die Gefässwandung und Eintritt in die Blutbahn, wo unter ungünstigen Bedingungen kein Absterben der Eindringlinge, sondern eine Vermehrung, eine Septicämie erzeugt wird. Ist hierbei auch die Menge des rom Einzelwesen gelieferten Giftes gering, so bedingt doch die colossale Anzahl der Mikroorganismen oine grosse, event. tödtliche Menge des Giftes." Sicher sind das Vorstellungen, die mit der Lehre von der Specificität der Bakterien und unseren allgemein bakteriologischen

1) Karlinsk : Zur Kenntniss des Bacillus enteritidis Gartner. Centralbl. f. Bakteriol. a. Parasitenkunde. Bd. YI. S, 289. 
und patholoyischen Kenntnissen wohl vereinbar sind. Aber es sind für die Classificirung des Bacillus enteridis doch höchstens wahrscheinliche Möglichkeiten, keine gesicherten Thatsachen '). -

Sehen wir nun von dieser Frage ab, so müssen wir weiter untersuchen, ob wir den gefundenen Bacillus als den Erreger der vorliegenden Krankheit ansprechen dürfen. Dass es sich etwa um nachträglich eingedrungene Fäulnissbakterien handelt, kann mit Sicherheit ausgeschlossen werden. Die Section wurde 13 Stunden nach dem Tode vorgenommen, die Leiche hatte in kalter Winternacht in einem kalten Raume gelegen, irgend welche Erscheinungen von Fäulniss fehlten vollständig; ferver aber liegen solche Bakterien, welche nachträglich in Leichen eindringen, mehr diffus vertheilt, sie liegen nicht in Heerden, sie liegen vor Allem nicht in Massen in den Blutgefässen, besonders den Capillaren; die Thatsache, dass die Bacillen in fast gleichmässiger Anordnung überall in den feinsten Capillaren deponirt waren, wie man dies besonders in den Glomerulusschlingen der Niere (Fig. $3 \mathrm{gl}$ ) sieht, beweist allein schon, dass hier eine Vermehrung von Bacillen im circulirenden Blute stattgefunden hatte. Auch sind gerade an dem Orte, von wo aus Fäulnissbakterien am ehesten nach dem Tode in andere Organe eindringen können, in der Darmsehleimhaut die Bacillen äberhaupt nicht $z u$ finden, vielmelr liegen sie dort ansschliesslich in den Gefässen der Muscularis. Es ist aber auch ebenso ausgeschlossen, dass die Bacillen etwa erst sub finem vitae in die Circulation eingedrungen sind. Dagegen spricht zunächst die wahrhaft ungeheure Menge von Bacillen, die auf jedem Schnitt und fast in jedem Organ zu finden waren; besonders in der $\mathrm{Mil} z$ waren Gefässe oft so vollgepfropft mit Bacillen, dass sie bereits bei 100 facher Vergrösserung als solche erkannt werden kounten. Ferner sah man in den Gefüssen, die überhaupt oft bedeutend mehr Leukocyten enthielten, als normal, die Bacillen nicht selten in weissen Blutkörperchen liegen. Am beweisendsten sind aber die Ver-

1) Da sowohl der Gärtner'sche, wie mein Bacillus in den Culturen ziemlich rasch seine pathogenen Eigenschaften verliert, so habe jeh versucht, ob diese pathogenen Wirkungen etwa durch anaërobiose Züchtıng.(vgl. Hüppes's Erfolge beim Vibrio der (holera asiatica) wiedererlangt werden können. Bis jetzt jedoch sind die Ergebnisse noch nicht ganz eindeutig. 
hältnisse in der meamonischen Lunge; hier liegen die Bacillen immer mitten im Exsudat zwischen Zellen und Ribriofäden, hierhin mussten sie also gelangt sein zu einer Zeit, wo das Exsudat noch nicht erstart war. Die ganze anatomische Vertheilung der Bacillon ist also eine derartige, dass sie sowohl als die Erreger der Septicämie, wie der Pneumonie aufgefasst werden können. Jies wird nun weiter unterstützt durch die pathologischen Eigenschaften, die wir im Thierversuch an tem Bacillus kenten gelornt haben. Immer besitzt or die Fähigkeit eine Septicämie zu erzeugen, inmer ruft er an der Impfstelle fibrinöshämurhagische Entzündung hervor, wobei er auch in der Weiterverbreitung cine gewisse Vorliebe für die Pleura aufweist. Nach alledem wird man zagestehen mïssen, dass die Vorbedingungen erfillt sind, um unseren Bacillus für den Erreger der vorliegendon Septioumie and septischen Pnemonie zu erklären.

Nun noch einige Bemerkangen über das Verhältniss unserer Erkrankung zur Winkel schen Krankheit und äber den Modus der Ansteckung.

Es lian ja kein Zweifel obwalten, dass sowohl in dem klinischen Verlauf der Erkrakung, wie in dem auatomischen Befund gewisse Aebnlichkeiten mit der Winkel'schen Krankheit bestehen. Die Wiokel'sche') Krabliheit wirl charakterisirt durch Cyanose, Icterus, Hämoglobinurie und raschem Collaps bei völig fieberlosem Verdauf. Die Respirationsbeschwerten, der sehr rasche Verdauf der Trankheit, die Neigung zu Blutungon und fettigen Bntartungen, sowie die Lenkocytose, fernor das Fehlen jeglicher Tabel- und Nabelgefasserkrankung würle mit den Befunden bei der Winkel'sehen Krankheit äbereinstirnmen. Allein der Befund in den Nicren ist ein so völlig verschiedener, dass an eine vollständige Uehereinstimmung uicht gedacht werden kam. Während dort die Harnkanälohen stets körniges Hämoglobin, niemals erbaltene Blutkörperchen enthielten, waren in unserem Fall nur spärliche, richtige Blutungen zu titden; Was die ganze Beurtheilung der Winkel'schen Krankheit anbetrifft, so muss man ja dazu neigen, dieselbe für eine Infectionskrankheit zu erklären. Die Thatsache, dass in der Dresdener Epidenie nur in zwei Fällen Bakterien gefunden wurden, spricht nicht

1) Winlse], Deutsche Hedicin. Wochenscbr. 1879. No. 24, 25 n. 33-35. 
dagegen, denn sowohl dic Cultur- wie die Färbemethoden zum Bakteriennachweis waren damals, wie bekannt, noch nicht zu der jetzigen Höhe ausgebildet.

Es ist ja anch in neuerer Zeit von Strelitz ${ }^{2}$ ein Fall beschrieben worden, in dem Streptokokken als die Erreger der Krankheit angesprochen wurden. Es ist daher denkbar, dass der Gärtner'sche Bacillus in Beziehung zur Winkel'schen Krankheit steht und dass unser Fall nur in Folge seiner besonderen Localisation nicht elenfalls zo Hämoglobinurie führte. Es wäre daher vorkommenden Falls erwünscht, besonders auf diesen Bacillus zu fahnden. Allein nach dem jetzigen Stand unserer Kenntnisse können wir den rorliegenden Fall nicht zur Winkel'schen Kraukheit rechnen und müssen ihn vielmehr als ächte Septicümic auffassen.

Es fragt sich nun, von wo aus die Bacillen in den Körper eingedrungen sind. Dabei kommen als Eingangspforten in Betracht der Nabel, die Athmungsorgane und der Verdauungstractus. Am leichtesten können wir den letzteren ausschliessen. Denn besonders der mikroskopische Befund im Jarm spricht dagegen, wurden doch hier auf der Schleimhantoberlächo unsere Bacillen vollkommen vermisst. Gegen den Nabel als Eingangspforte würde der Umstand sprechen, dass der äussere Nabel und die Nabelgefässe keine Veränderung darbot. Selbst mikroskopisch war ja selbst das perivasculäre Bindegewebe frei von Veränderungen. Allein man wird Runge darin Recht geben müssen, dass wenigstens die Möglichkeit besteht, dass das septische Gift längs der Nabelgefässe in den Körper eindringt ohne an ihm selbst pathologische Veränderungen zu hinterlassen. Dazu kommt, dass nach demselben Autor die septische Preumonie eine der häufigsten Complicationen bei einer vom Nabel ausgehenden Sepsis ist ${ }^{2}$ ). Man müsste dann annchmen, dass die in's Blut eingedrungenen Bacillen aus irgend einem unbekannten Grundo im Unterlappen der linken Lunge besonders günstige Ernährungsbedingungen gefunden haben und daher dort die Pneumonie erzeugten. Aus der Krankengeschichte würde ja die primäre Ansiede-

') Ein Fall von Winkel'scher Krankheit. Archiv für Kinderheilkunde. Bd.11. S. 11.

3) H. Runge, Die Krankbeiten iu den ersten Lebenstagen. S. 153 u. 161 . 
lung in dem Blute nicht gerade unwahrohemlich sein, dem die ersten Erscheinungen waren allgemeiner Natur und auch die Diarrhöen könnten aul eine Einwirkung des septischen Giftes vom Blute aus bezogen werden. Auch den mikroskopischen Befund in der rechten lunge könnte man zur Stätze dieser Anschauung heranziehen. Hier sah man ja, wie nur an einer Stelle von dem Blute aus zugleich mit Blutkörperchen die Bacillen in den Alveolarraum eindrangen. Bei näherer Untersuchung erscheint jedoch auch dieser Modus unmöglich. Obgleieh ich selbst mich anfangs der Annahme ciner embolischen Pneumonie zuneigte, so wurde ich doch schon oft etwas schwankend, als ich bei ausgedehnter Untersuchung nirgends etwas fand, was etwa die Ansiedelung der Bacillen in der linken Lunge hätte erklären können. Weder Haare noch Hautepithelien, die man ja doch sonst so oft selbst in den Lungen gosunder Neugebomer findet, waren nachzuweisen. Endlich zeigen alle Erfahrungen und Thierversuche, welche über den Bacillus Gartner vorliegen, dass derselbe gerade an der Eintrittspforte mit Vorliebe fibriuös-hämorrhagische Entzündung hervoruft. Und gerade der von mir gezüchtete Organismus hatte diese Eigenschaft, wio die Thierversuche ergeben, in besonders hohem Maasse. Es bleibt daher wohl nichts anderes übrig, als die linke lunge fär den primären Heerd $z u$ betrachten. Alle anderen noch möglichen Eingangspforten, wie Tonsillen und Magen, würden wiederum dieselbe Schwierigkeit aufweisen, die linksseitige lobäre Pneumonie zu erklären, denn die embolischen Pneumonien pflegen häufiger rechts zu sitzen und fast niemals vollkommen zu confluiren. Wem die ersten Erscheinungen von Seiten der Athmungswege später auftraten, wie ron Seiten des Darms, und weun selbst ipäter physikalisch keine Lungenerkrankung nachweisbar war, so erklärt sich dies aus der Schwierigkeit der Untersuchung Neugeborner, sowie aus den toxischen Fähigkeiten unseres Bacillus. Das von ihm an der Fingangsstelle bei seiner Vermehrung ab gesonderte Gift konute bereits auf den Darm wirken, bevor es zu schwereren localen Veränderungen gekommen war; sind ja doch bei allen septischen Prozessen Diarrhöen ausserordentlich häufig. Auf welche Weise nun das Kind den Bacillus in sich aufgenommen hat, ist schwer an sagen. Ob es denselben bereits 
während des Durchtritts durch die äusseren Genitalien der Mutter, etwa aus dem Darm dieser aspirirte, oder ihn erst später aufnahm, kann auch nicht vermuthungsweise entschieden werden. Die Angabe von Karlinski, dass der Bacillus Gärtner auch im Đarm normaler Individuen vorkommt, könnte ja allerdings die erste Möglichkeit stützen. Da auch die Mutter kurz nach dem Tode des Kindes fieberhaft an einer Parametritis erkrankte, so erschien es mir des Versuches werth, die Genitalien der Frau auf das Vorhandensein des Gärtner'schen Bacillus zu untersuchen. Ich entnahm unter aseptischen Vorsichtsmaassregeln aus dem Cervixschleim etwas Material und brachte dasselbe in ein Reagensglas mit steriler Bouillon. Etwa eine Viertelstunde später legte ich dann davon Agar- und Gelatineplattenculturen an. Dieselben blieben grösstentheils steril, keinenfalls enthielten sie den Bacillus Gärtner. Diese Frage muss ich also vollkommen offen lassen.

Jedenfalls hielt ich es für geboten, den vorliegenden Fall ausführlicher mitzutheilen; denn jemehr man Runge darin Recht geben muss, dass eine septische Infection durch Aspiration fauliger Secrete ein höchst seltenes Ereigniss ist, um so mehr muss man derartige Fälle genauer besprechen, in denen wenigstens die Untersuchung der anderen Eingangspforten nicht vernachlässigt und auch für die Entstehungsursache ein positives Ergebniss erzielt wurde.

\section{Erklärung der Abbildungen. Tafel I.}

Fig. 1. Alveole aus dem Unterlappen der linken Lunge. Sublimathärtung. Paraffineinbettung, Färbung mit Boraxmethylenblau. Vergr. Zeiss homog. Immers. $\frac{1}{T 2}$, Oc. 4 . Die rothen Blutkörperchen grün, die Bacillen und Leukocyten blau, Fibrinfäden grün.

Fig. 2. Schnitt aus der Leber. Behandlung und Vergrössernng wie in Fig. 1.

Fig. 3. Glomerulus (gl) der linken Niere, in den Capillaren reichlich Bacillen enthaltend. Bei art Arterie wit vielen Lenkocyten und Bacillen. Vergr. Zeiss $\frac{1}{12}$, Oc. 2.

Fig. 4. Bacillenhaufen in der Nilz. Vergr. wie Fig. 3.

Fig. 5. Capillaren aus der rechten Lunge mit Bacillen voligepfropft. Zeiss $\frac{1}{1} \frac{1}{2}$, Oc. 4.

Fig. 6. Bacillen aus einer Reincultur auf Zuckergelatine zeigt die ungefärbten Pole. Vergr. wie Fig. 3.

Fig. 4 u. 6, sowie die Zinkographie sind mit dem Zeichenapparat gezeichnet. 